\title{
On-road testing and characterization of the exhaust emissions of light-duty vehicles
}

\author{
J. Merkisz ${ }^{1}$, J. Pielecha ${ }^{1} \&$ W. Gis ${ }^{2}$ \\ ${ }^{I}$ Poznan University of Technology, Poland \\ ${ }^{2}$ Motor Transport Institute, Warsaw, Poland
}

\begin{abstract}
In order to measure the concentration of toxic compounds a mobile analyzer for toxic tests SEMTECH DS by SENSORS Inc. was used. In the study the results of the vehicle emission tests in the road conditions were presented, as this was the only way to obtain the information on real vehicle emissions. They include information on the emissivity of the vehicles in operation and deal with the real conditions of the vehicle motion. Reliable measurement results were obtained, which were verified in simulated conditions on a chassis test bed. The obtained data were used to specify the dependence characteristics for the influence of the dynamic engine properties on the harmful compound emissions. The obtained data enabled one to define the vehicle emission factor, which can be used to classify fleets of vehicles in relation to toxic compounds emissions that differ e.g. in production data, i.e. limits of exhaust emissions, mileage of vehicles or operation conditions.
\end{abstract}

Keywords: exhaust emission, road test, on-board measurement.

\section{Introduction}

These days one can observe a strong tendency to deal with environmental perils from the automotive industry in global terms. The regulations that allow the operation of vehicles (homologation tests and production conformity tests), periodical technical check-ups and other laws directly and indirectly related to the production, operation and management of products of civilization treat the problem of environmental protection on a full scale [1-3]. Over the years in each country there were different systems of tests and vehicle exhaust emission control, however, for some time there has been a well-developed unification. The control of toxic emissions is also held worldwide through the balancing of global 
emissions from various sources of operations, including the automotive industry 'extra-automotive use of engines. In Europe the coordination of balancing environmentally harmful emissions is held within the CORINAIR (Coordination of Information on the Environment) program.

The growing number of cars in the world and the pollution of the environment result in higher requirements as far as the emission of exhaust components is concerned. The present level of technical and technological advancement in all of the branches of industry, including all types of transport, causes increased requirements for the production of tools for emission measurement. In order for these requirements to be fulfilled to the necessary extent according to the regulations, which change from time to time, it was necessary for the industry to concentrate on this issue. The studies on the emission of toxic components are a complex process. Contemporary emission analyzers require special laboratory conditions and the homologation procedures include engine and chassis dynamometer tests, which do not reflect the real onroad emissions. The latest results of studies conducted in real conditions show that, in the case of some emission components, certain emissions are higher by several hundred per cent. Thus, there is a tendency to legitimize the measurement of the emission in the real conditions of vehicle operation.

\section{Testing methods}

The measurement of emissivity was carried out in the road conditions in the city of Poznan. The tests were conducted on the main the roads of the city in the afternoon, with a moderate traffic. The conditions were selected in such a way as to enable the tests results to be compared with the NEDC homologation test with reference to which the emissivity indicators were introduced. The specified tour was characterized by parameters similar to the NEDC test as far as the road length, driving time and average speed value are concerned (Tab. 1). The tour profile was diversified with respect to the altitude above sea level and the maximum difference was $25.2 \mathrm{~m}$. As the tests were held for one vehicle fuelled with gasoline or LPG (such vehicles are mainly operated in Poland) the table shows the average values for drives which were repeated five times. Differences in the values did not exceed $5 \%$ of the average value. The tests measured the concentration of $\mathrm{CO}, \mathrm{HC}$ and NOx for a vehicle fuelled with gasoline and LPG and then with the use of GPS and diagnostic system data the road emissions were specified.

Table 1: Characteristics of a test (gasoline, LPG) and comparison with the NEDC cycle.

\begin{tabular}{|l|l|l|l|}
\hline & Gasoline & LPG & NEDC \\
\hline Total duration $[\mathrm{s}]$ & 1329 & 1335 & 1180 \\
\hline Max. speed $[\mathrm{km} / \mathrm{h}]$ & 70.8 & 69.2 & 120 \\
\hline Average speed $[\mathrm{km} / \mathrm{h}]$ & 32.4 & 29.06 & 33.6 \\
\hline Length $[\mathrm{m}]$ & 11,941 & 11,810 & 11,007 \\
\hline
\end{tabular}




\section{Experimental set up}

\subsection{Vehicle}

The object of the tests was a Dodge Grand Caravan (for technical parameters see Tab. 2) fuelled with gasoline or LPG. The choice of this vehicle was justified to a great extent by the fact that the two fuels are mostly used in Poland [4]. At the same time one shall observe that such vehicles are in conformity with the standard on emissions that was binding in Europe a few years ago (e.g. the tested vehicle was homologated according to the Euro 2 standard).

Table 2: Vehicle characteristics.

\begin{tabular}{|l|c|}
\hline \multicolumn{1}{|c|}{ Parameter } & Value \\
\hline Car & Dodge Grand Caravan \\
Engine & Gasoline \& LPG \\
Transmission & Automatic \\
Cylinder & 6 \\
Engine volume & $3.3 \mathrm{dm}^{3}$ \\
Catalytic converter & yes - TWC \\
Mileage & 105,000 miles \\
OBD II protocol & ISO-9141-2 \\
\hline
\end{tabular}

Table 3: $\quad$ Characteristics of mobile exhaust analyzer SEMTECH DS.

\begin{tabular}{|c|l|c|}
\hline Parameter & \multicolumn{1}{|c|}{ Measurement method } & Accuracy \\
\hline 1. Emission & & \\
$\mathrm{CO}$ & NDIR, range 0-8\% & $\pm 3 \%$ \\
$\mathrm{HC}$ & FID, range 0-10 000 ppm & $\pm 2 \%$ \\
$\mathrm{NO}_{\mathrm{x}}$ & NDUV, range 0-2500 ppm & $\pm 3 \%$ \\
$\mathrm{CO}_{2}$ & NDIR, range 0-20\% & $\pm 3 \%$ \\
\hline
\end{tabular}

\subsection{Measurement instruments}

In order to measure the concentration of toxic compounds a mobile analyzer for toxicity tests SEMTECH DS by SENSORS Inc. [5-7] was used. The analyzer allowed the measurement of harmful compounds concentration with the simultaneous measurement of the mass intensity of exhaust gases. The exhaust gas introduced to the analyzer through a probe maintaining the temperature of $191^{\circ} \mathrm{C}$ was then filtered out of the particle matter (CI engine) and directed to the flame-ionizing detector (FID) where the hydrocarbons concentration was measured. Then, the exhaust gas was cooled down to the temperature of $4^{\circ} \mathrm{C}$ and the measurement of the concentration of nitric oxides (NDUV analyzer), carbon monoxide, carbon dioxide (NDIR analyzer) and oxygen followed in the listed order. It is possible to add data acquired directly from the vehicle diagnostic system to the central unit of the analyzer and make use of the GPS signal (Tab. 3 and Figs 1 and 2). 
In the tests the measurements of toxic compounds emission were performed and, for comparison, signals from an on-board diagnostic system were also registered (standard SAE J1850), e.g., engine speed, load, vehicle speed and intake air temperature [8-12]. Some of these signals served to specify the time density maps presenting the share of the operating time of a vehicle in the real operation. The GPS localization signal was used for further visualization of the obtained data.

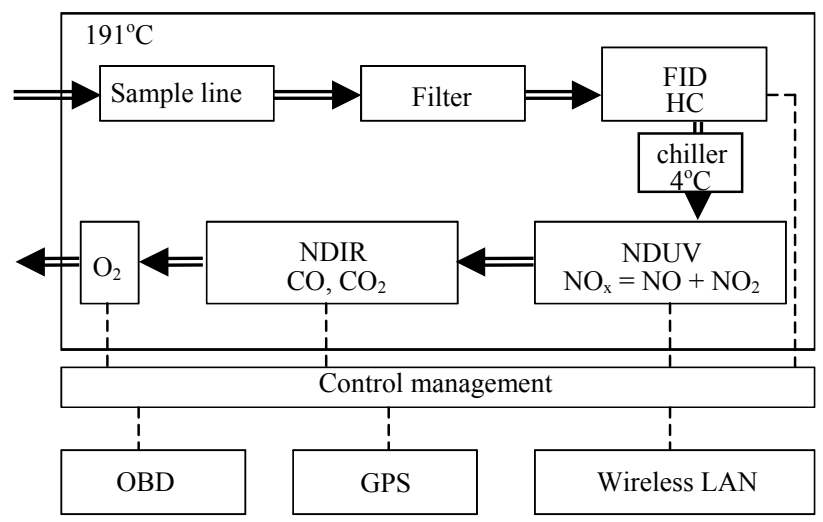

Figure 1: A diagram of mobile analyzer SEMTECH DS; exhaust gas flow channels $(===)$ and electrical connections circled $(---)$.
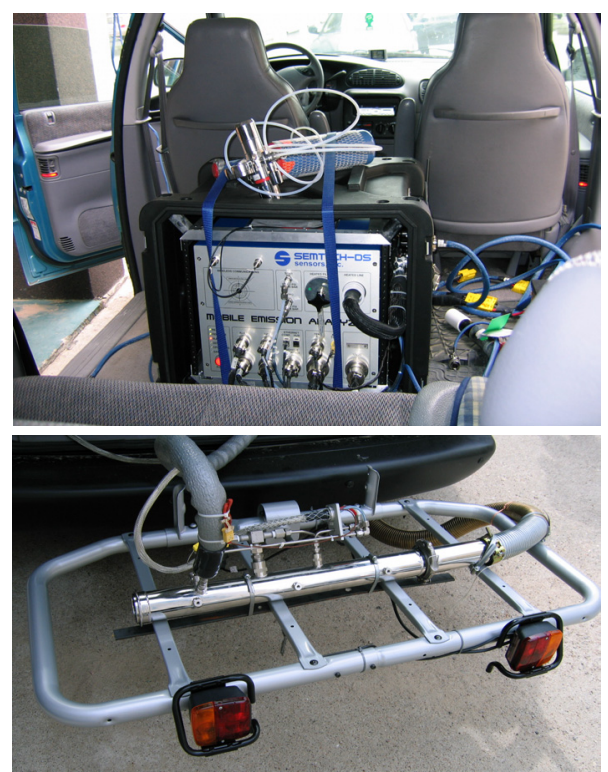

Figure 2: View of the SEMTECH DS analyzer fitted in a vehicle (top: analyzer's central unit, bottom: exhaust gas meter). 


\section{Experimental results}

The registered concentration values of toxic compounds (i.e. CO) were presented for the purpose of comparison for a car fuelled with petrol and LPG. Such an interpretation is a better reflection of the differences in concentration of certain compounds as it also draws a picture of traffic conditions in which such concentration values were observed. At the same time the conditions of engine operation become visible, which should be a subject of a stricter evaluation in terms of emission and which should focus research efforts in order to reduce the harmful effects of powertrain on the environment. Fig. 3 features a comparison of carbon monoxide concentration: for a gasoline fuelled engine it is much lower and the time of its high concentration is short, which is a result of the operation of a catalytic converter. For LPG fuelled engines the CO concentration is much higher - which may prove an insufficient adjustment of an engine to combust LPG. On the other hand, LPG fuelling was not a factory built system but only an additional system fitted into the vehicle.

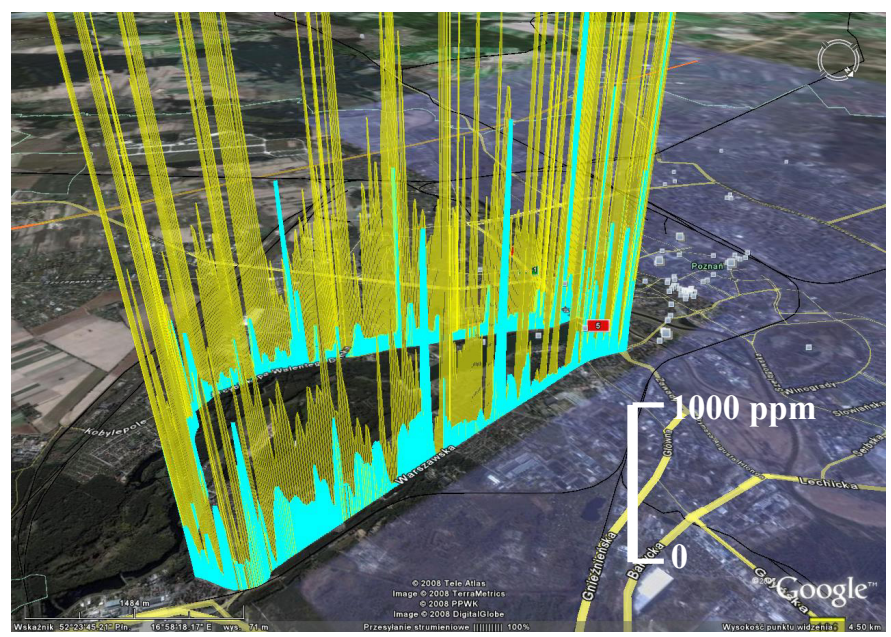

Figure 3: Concentration of $\mathrm{CO}$ during the test of exhaust emissions; - Gasoline, - LPG.

\section{Analysis}

The obtained data were used to specify the dependence characteristics for the influence of dynamic engine properties on harmful compounds emissions. The dynamic engine properties were indirectly taken into account, using all the speed range and the range of acceleration calculated for the city traffic to prepare a matrix of emission intensity. The data used were averaged within each speed and acceleration range, which generated characteristics of the vehicle operation in each range and characteristics of the emission matrices of each harmful 
compound. The greatest share of the engine operation in the studied traffic conditions was obtained for minimum and medium speeds and zero vehicle acceleration.

The highest emission of carbon monoxide and hydrocarbons falls within the maximum values of vehicles acceleration $\left(0.4-0.8 \mathrm{~m} / \mathrm{s}^{2}\right.$ for gasoline, Fig. 4). For the LPG the highest emission of these two compounds is observed in the middle of the graph (Fig. 5). What particularly draws our attention here is the area of higher $\mathrm{CO}$ and $\mathrm{HC}$ emission: for gasoline it occurs for the positive acceleration values only while for the LPG it occurs for negative values as well - during engine braking. This means that the ECU does not cut off the fuel as promptly as is in the case of gasoline.

The area of an increased emission of nitric oxides (Fig. 6) falls within the range of increased speeds of a vehicle and increased acceleration of a vehicle i.e. a considerable engine load. This is related to the enhanced dose of fuel and the increase of the engine speed at the same time.

a)

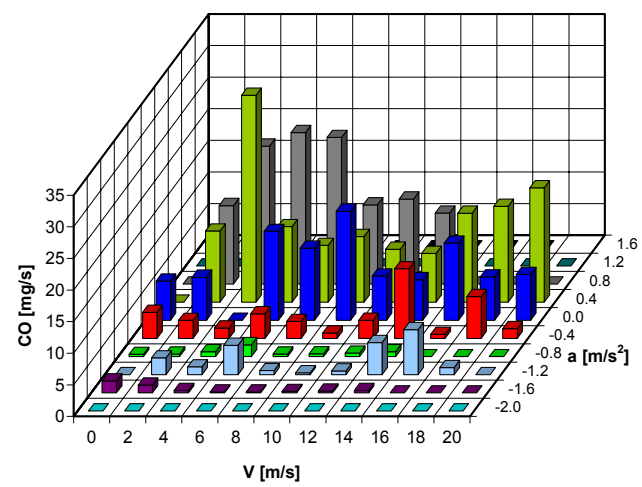

b)

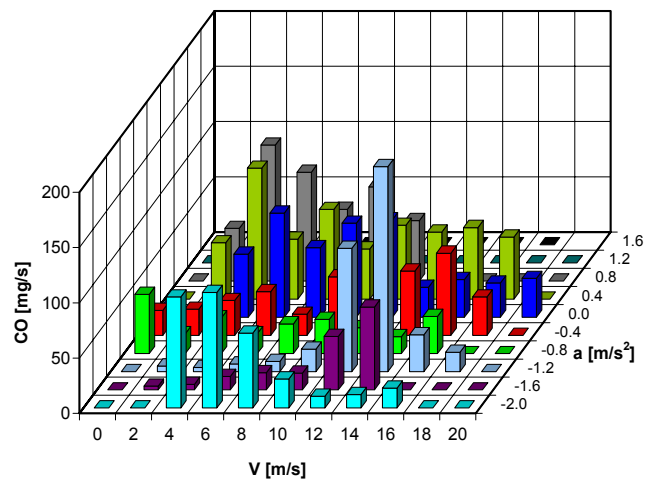

Figure 4: Characteristics of emission intensity of carbon monoxide in each speed and acceleration range in city traffic conditions: a) gasoline; b) LPG. 
a)

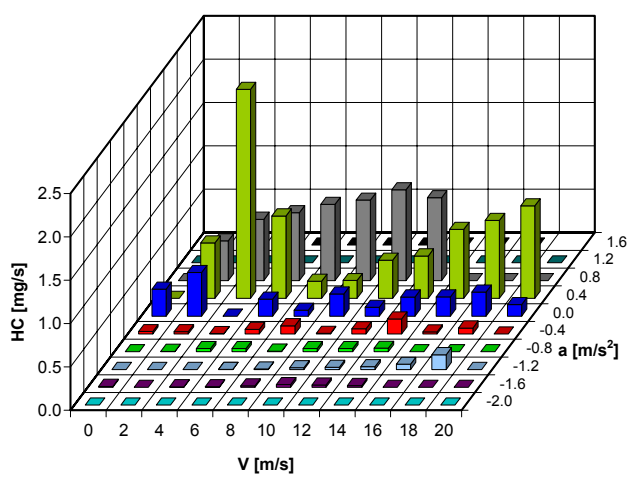

b)

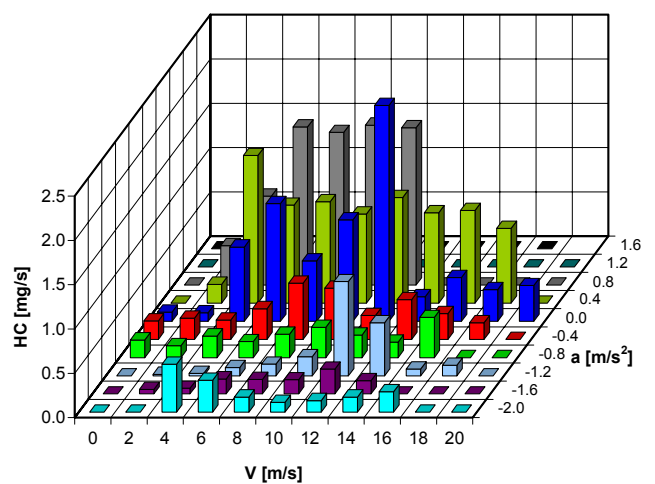

Figure 5: Characteristics of emission intensity of hydrocarbons in each speed and acceleration range in city traffic conditions: a) gasoline; b) LPG.

The obtained results of a vehicle driving time in the conditions determined by its speed, acceleration and intensity of harmful compounds were verified in the European homologation test NEDC. This comparison was used subsequently to specify the value of the emission increase from a vehicle in the real conditions in relation with the conditions of a vehicle operation in the homologation test.

Having compared the share of the driving time of a vehicle within the areas of a vehicle speed and acceleration in the road and homologation test (Fig. 7) a similarity of the both obtained characteristics can be observed. Compatibility of the compared characteristics for a breakdown of the occurrence of a vehicle driving time share has been maintained. In the NEDC test the share of a vehicle drive at minimum speed and zero acceleration is higher. However, for real conditions the area of the used speeds and acceleration of a vehicle is higher. The relative comparison of the values reveals the discrepancies, which reach the values above $100 \%$ for the same ranges of speed and acceleration of a vehicle. 
a)

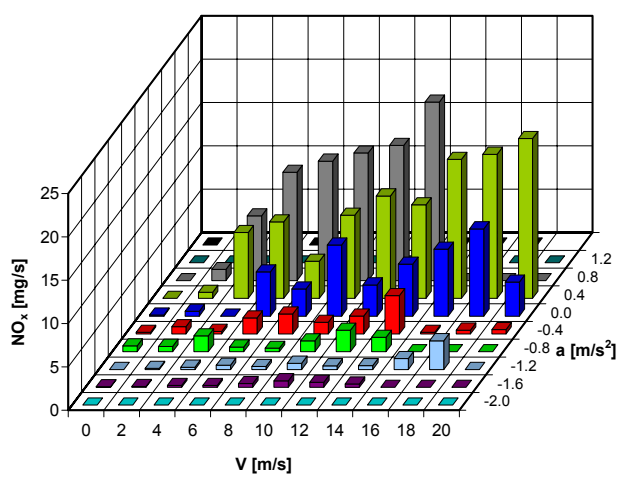

b)

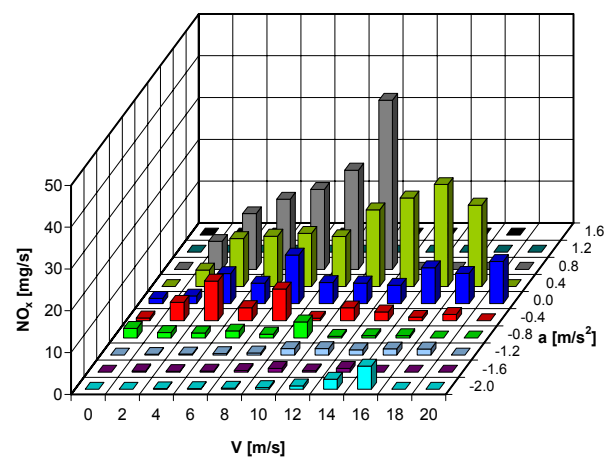

Figure 6: Characteristics of emission intensity of nitric oxides in each speed and acceleration range in city traffic conditions: a) gasoline; b) LPG.

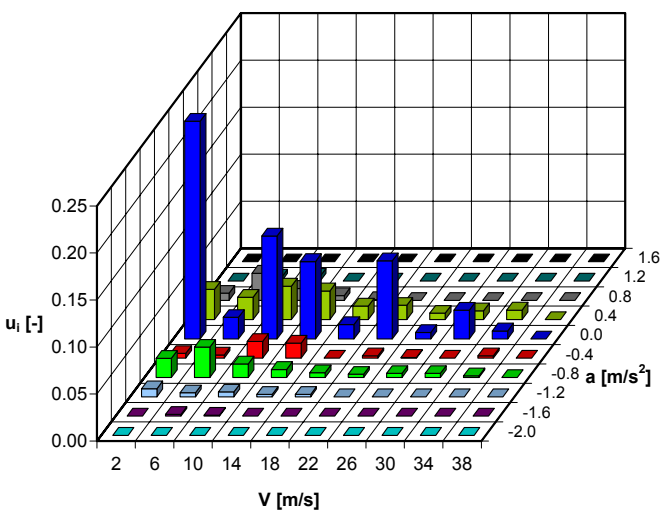

Figure 7: Characteristics of the use of the vehicle operating time in each range of speed and acceleration for the conditions of the NEDC test. 


\section{Quantity indicators of emissivity}

Quantity indicators of a vehicle emissivity for a certain engine fuelling system were presented in the form of a cumulated mass of a certain harmful compound (Fig. 8). The comparison proves that an LPG-fuelled engine emits much more of harmful compounds than an engine fuelled with petrol (for a non-factory gas installation). The biggest differences were observed for carbon monoxide (about 5 times higher - Fig. 9), for hydrocarbons it was 2 times higher, while the lowest increase was observed for nitric oxides - about $50 \%$ higher.

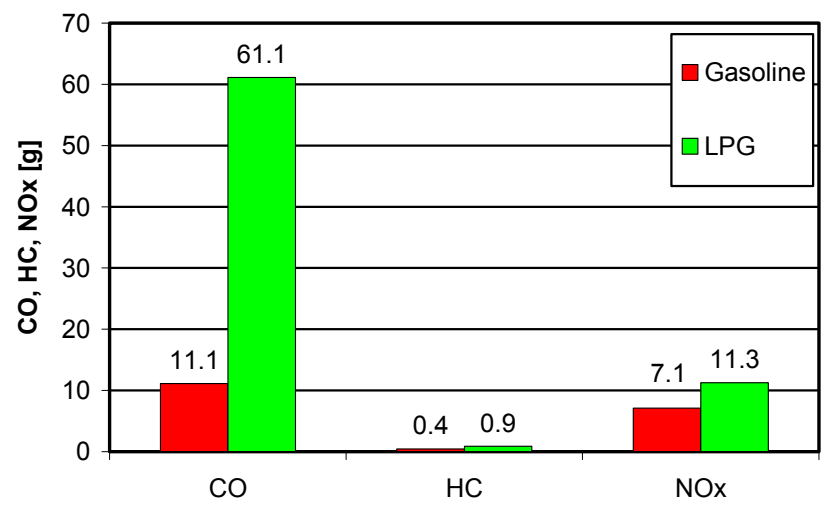

Figure 8: Cumulated mass of harmful compounds emitted during the research test for a gasoline and LPG-fuelled engine.

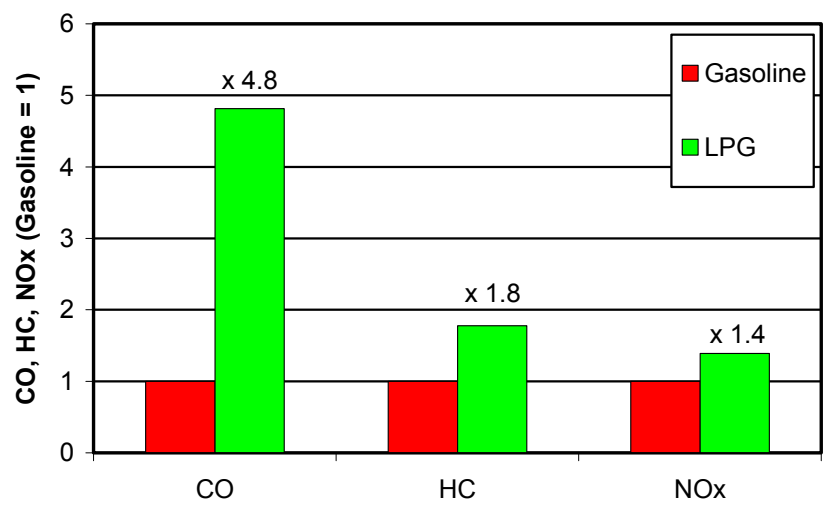

Figure 9: A comparison of the mass of the emitted toxic compounds for a gasoline and LPG-fuelled vehicle. 
With the use of values of cumulated emission of harmful compounds and the values registered from the GPS localization system the road length during the test was determined and then average road emission was specified for each harmful compound (Fig. 10). The comparison proves that only the emission of carbon monoxide for a gasoline-fed engine does not exceed acceptable values allowed by the standard (binding for this vehicle). The remaining road emission values exceed these values. That means a higher road emission of a vehicle during operation than during a homologation test.

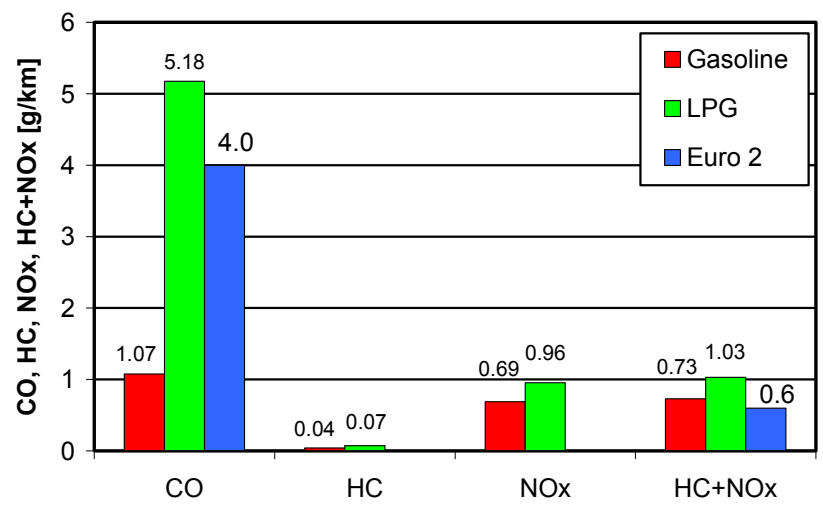

Figure 10: A comparison of road emission values in the road test for a petrol and LPG-fuelled vehicle and the value of emissions set forth by the Euro 2 standard.

\section{Conclusion}

The comparison of emissivity of a petrol and LPG-fuelled vehicle points to an increased emissivity of and LPG-fuelled vehicle. This results in a higher emission of carbon monoxide (over 5 times higher than for the gasoline fuelling) and also in a higher emission of hydrocarbons and nitric oxides (emission increased respectively 1.8 and 1.4 times).

The analysis of the data proves that the emission values obtained in the NEDC homologation test for a tested vehicle (in accordance with Euro 2 standard) and the values in the real operation differ from each other. These differences in the case of some compounds are significant and amount to:

- for a petrol-fuelled engine:

- CO emission is $70 \%$ lower,

- emission of hydrocarbons and nitric oxides is $20 \%$ higher,

- for an LPG-fuelled engine:

- $\mathrm{CO}$ emission is $30 \%$ higher,

- emission of HC and NOx is $70 \%$ higher.

The obtained data enabled to define the vehicle emission factor which can be used to classify fleets of vehicles in relation to toxic compounds emissions that 
differ e.g. in production date (limits of exhaust toxicity, mileage of vehicles or operating conditions).

The results of the tests carried out in the real conditions show that in the case of some exhaust toxic compounds this emission is several hundred per cent higher. Therefore, one can observe a tendency to legitimize the emission measurement of harmful compounds in the real operation conditions of vehicles in Europe.

\section{References}

[1] Directive 98/69/EC of the European Parliament and of the Council of 13 October 1998 Relating to Measures to be Taken Against Air Pollution by Emissions from Motor Vehicles and Amending Council Directive 70/220/EEC, Official Journal L 350, 28.12.1998.

[2] Processing CITA Conference „Global Perspective on Road-worthiness Enforcement", organized by International Motor Vehicle Inspection Committee. Chicago 24-28.05.2005.

[3] Zhao, F.F., Technologies for Near-Zero-Emission Gasoline-Powered Vehicles. SAE International, Warrendale 2007.

[4] Merkisz, J., Gis, W., European On-Board Diagnostic System in Automotive Vehicles in Poland. 2nd World Congress on Maintenance and 19th Brazilian Congress on Maintenance, 2004.

[5] Korniski, T., Gierczak, C., Wallington, T., Laboratory Evaluation of the 2.5 Inch Diameter SEMTECH ${ }^{\circledR}$ Exhaust Flow Meter with Gasoline Fueled Vehicles. Sensors 4th Annual SUN (SEMTECH User Network) Conference, 2007.

[6] Shahinian, V.D., SENSORS tech-ct Update Application Soft-ware for SEMTECH Mobile Emission Analyzers. Sensors 4th Annual SUN (SEMTECH User Network) Conference, 2007.

[7] Sharp, C.A., Feist, M., Results of the HDIUT Gaseous PEMS Measurement Allowance Program and Update on PM Program Status. Sensors 4th Annual SUN (SEMTECH User Network) Conference, 2007.

[8] Gao, Y., Checkel, M.D., Emission Factors Analysis for Multiple Vehicles Using an On-Board, In-Use Emissions Measurement System. SAE World Congress, 2007-01-1327, 2007.

[9] Gao, Y., Checkel, M.D., Experimental Measurement of On-Road CO2 Emission and Fuel Consumption Functions. SAE Congress, 2007-01-1610, 2007.

[10] Greening, P., European Light-Duty \& Heavy Duty OBD - Legislative Update. On-Board Diagnostic Symposium: Light and Heavy Duty, Lyon 2007.

[11] McCarthy, M., Update on Light Duty OBD II. On-Board Diagnostic Symposium: Light and Heavy Duty, Lyon 2007.

[12] Tsinoglou, D.N., Koltsakis, G.C., Samaras, Z.S., Performance of OBD Systems for Euro 4 Level Vehicles and Implications for the Future OBD Legislation. Onboard-Diagnose II, ed. O. Predelli, Expert Verlag, 2007. 